\title{
Resolving cryptic species complexes in marine protists: phylogenetic haplotype networks meet global DNA metabarcoding datasets
}

\author{
Daniele De Luca $\mathbb{( D}^{1,3} \cdot$ Roberta Piredda $\mathbb{( D}^{1} \cdot$ Diana Sarno $^{2} \cdot$ Wiebe H.C.F. Kooistra $\mathbb{( D}^{1}$
}

Received: 26 June 2020 / Revised: 23 December 2020 / Accepted: 14 January 2021 / Published online: 15 February 2021

(C) The Author(s) 2021. This article is published with open access

\begin{abstract}
Marine protists have traditionally been assumed to be lowly diverse and cosmopolitan. Yet, several recent studies have shown that many protist species actually consist of cryptic complexes of species whose members are often restricted to particular biogeographic regions. Nonetheless, detection of cryptic species is usually hampered by sampling coverage and application of methods (e.g. phylogenetic trees) that are not well suited to identify relatively recent divergence and ongoing gene flow. In this paper, we show how these issues can be overcome by inferring phylogenetic haplotype networks from global metabarcoding datasets. We use the Chaetoceros curvisetus (Bacillariophyta) species complex as study case. Using two complementary metabarcoding datasets (Ocean Sampling Day and Tara Oceans), we equally resolve the cryptic complex in terms of number of inferred species. We detect new hypothetical species in both datasets. Gene flow between most of species is absent, but no barcoding gap exists. Some species have restricted distribution patterns whereas others are widely distributed. Closely related taxa occupy contrasting biogeographic regions, suggesting that geographic and ecological differentiation drive speciation. In conclusion, we show the potential of the analysis of metabarcoding data with evolutionary approaches for systematic and phylogeographic studies of marine protists.
\end{abstract}

\section{Introduction}

The term 'cryptic species' is used for morphologically indistinguishable taxa for which there is evidence (genetic, ecological, behavioural, biological, etc.) that they belong to different evolutionary lineages [1,2]. Groups of such taxa are commonly referred to as 'cryptic species complexes.' Cryptic species may have diverged recently and not yet have become morphologically distinct, or they are distantly

These authors contributed equally: Daniele De Luca, Roberta Piredda

Supplementary information The online version contains supplementary material available at https://doi.org/10.1038/s41396021-00895-0.

Wiebe H.C.F. Kooistra

wiebe.kooistra@szn.it

1 Department of Integrative Marine Ecology, Stazione Zoologica Anton Dohrn, Naples, Italy

2 Department of Research Infrastructure for Marine Biological Resources, Stazione Zoologica Anton Dohrn, Naples, Italy

3 Present address: Department of Biology, Botanical Garden of Naples, University of Naples Federico II, Naples, Italy related but retained their ancestral morphology or converged morphologically $[3,4]$.

Recent molecular taxonomic studies have uncovered remarkably high cryptic species diversity in marine planktonic protists [5-7]. Originally such taxa were believed to be lowly diverse because potentially high dispersal opportunities in the open sea leave little opportunity for genetic differentiation even at a global scale [8-12]. Unfortunately, exploring geographic patterning of cryptic species by traditional means, i.e. of sampling and examining large numbers of specimens from all over the oceans, is a daunting task. The few truly global biogeographic studies of such species complexes to date $[13,14]$ reveal that the individual species can be cosmopolitans in their own right or be geographically more confined.

Exploration of species distribution patterns in marine planktonic protists requires accurate species delimitation $[15,16]$. Cryptic species complexes in protists are usually explored by comparing nucleotide differences on selected DNA markers with differences in the ultrastructural, biochemical, biological or ecological properties of selected strains [13, 16-18]. Classically, nucleotide data are gathered through Sanger sequencing [19-21]. If genetic distances or bootstrap values justify independent evolutionary lineages, 
Fig. 1 Light microscopy photographs of Chaetoceros curvisetus and $C$.

pseudocurvisetus. a $C$. curvisetus; b $C$.

pseudocurvisetus. The size and shape of aperture between sibling cells (see arrows) are useful characters for distinguishing these taxa.
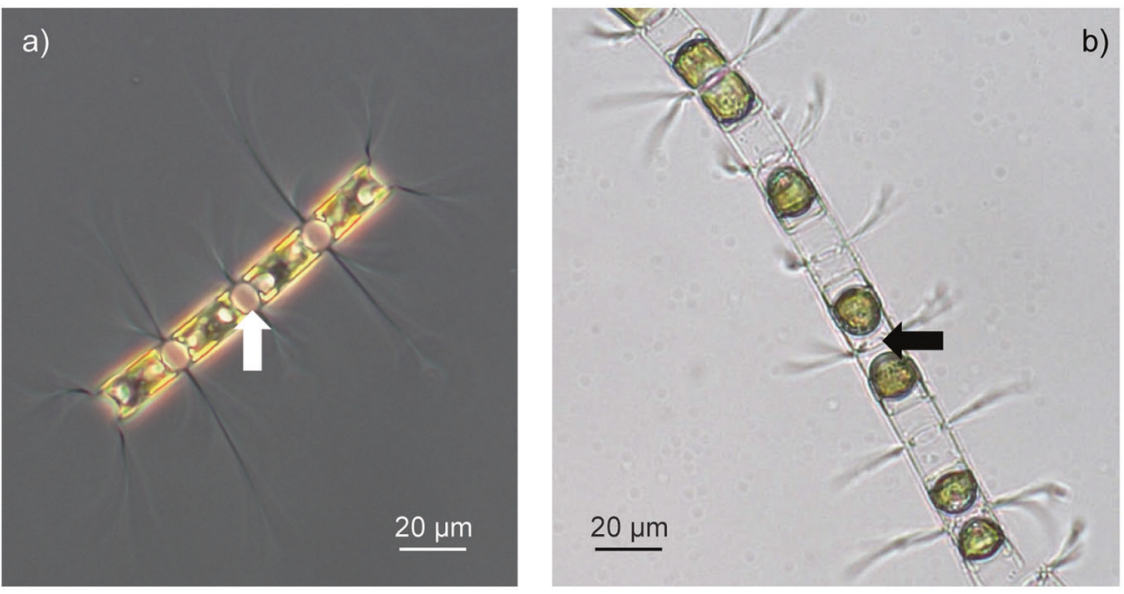

cryptic species are hypothesised. Yet, phylogenies depict sharply bifurcating speciation events and vertical changes within ancestor-descent lineages [22], but in case of recent speciation, attenuated gene flow may still persist between the sister lineages, which is visualised better in phylogenetic networks [22-24].

In recent years, high throughput sequencing of taxonomically discriminative barcode regions (HTS metabarcoding) has revolutionised our capacity to explore protistan diversity in environmental DNA samples [25]. However, finding a single, universal DNA barcode for a genetically heterogeneous assemblage like protists has revealed to be virtually impossible because of their long, independent, and complex evolutionary histories [26]. Several protistan DNA barcodes have been proposed, such as the D1-D2 or D2-D3 regions of the 28S rRNA gene [27-29], the ribosomal internal transcribed spacers ITS1 and ITS2 [30-32], the mitochondrial gene COI [33] or the chloroplastic gene $r b c \mathrm{~L}$ [34], but the $\sim 500 \mathrm{bp}$ variable V4 region of the $18 \mathrm{~S}$ rRNA gene has been preferred as the universal protistan barcode [26]. It is part of a multi-copy region present in all eukaryotes and includes conserved and variable regions useful for recognition at various taxonomic levels. The $18 \mathrm{~S}$ rRNA gene is used extensively to infer phylogenies and, consequently, reference sequences are available for a comprehensive set of species from across the protistan diversity [26, 35, 36]. The resolution of the 18S rRNA gene to distinguish species has been positively tested in several protistan taxa as foraminifera [37], dinoflagellates [38] and some diatoms $[35,39]$, but also negative results have been reported $[26,40]$. Global metabarcoding initiatives targeting marine protistan diversity used variable regions in the $18 \mathrm{~S}$ rRNA gene as metabarcode marker; Ocean Sampling Day 2014 (OSD) [41] selected the V4 variable region whereas Tara Oceans [42] used the shorter V9variable region. The resulting datasets have been used to uncover protistan diversity and distribution [43-46], to analyse their phylogenetic relationships $[47,48]$ and to delimit species $[49,50]$.

In the present study, we aim at delimiting species in the Chaetoceros curvisetus (C. curvisetus) species complex and at mapping their distribution patterns. The complex belongs to the diatoms, a diverse class of unicellular algae abundant in marine and freshwater habitats. Chaetoceros is arguably the most abundant and diverse genus in the marine planktonic diatoms. Its hallmark is constituted by setae-tubular silica extensions extending from the frustule and linking cells into chains. To date, only two species have been described: C. curvisetus Cleve and C. pseudocurvisetus Mangin (Fig. 1) [51]. Recent taxonomic studies uncovered that $C$. curvisetus consists of several genetically distinct taxa [39, 52, 53] with $C$. pseudocurvisetus resolved amongst these taxa, rendering the morphospecies $C$. curvisetus sensu lato paraphyletic.

Here we use the molecular information contained in the metabarcode data of OSD [41] and Tara Oceans, coupled with a phylogenetic network approach to identify cryptic species and assess their phylogenetic relationships. Reference sequences of the 18S rRNA gene of $C$. curvisetus species and close outgroup taxa [39] are used to gather reads putatively belonging to the species complex from these datasets. The extracted reads are sorted into haplotypes, which are used to generate phylogenetic networks. From the latter we delineate the species within the complex, explore the evolutionary relationships and possible gene flow among the species and assess their phylogeographic distribution and abundance in Longhurst's biogeographic provinces [54].

\section{Materials and methods}

\section{Reference molecular dataset}

The reference dataset comprised ten $18 \mathrm{~S}$ rRNA genes obtained from cultured strains, and retrieved from NCBI 
Table 1 List of 18S rRNA gene references for the V4 and V9 regions utilised for gathering taxa in the C. curvisetus species complex.

\begin{tabular}{lll}
\hline Taxon & Strain & GenBank accession number \\
\hline C. curvisetus SKLMP & YG033 & MG821562, V9 not included \\
C. curvisetus 1 & Na10C1 & MG972232 \\
C. curvisetus 2 & Na1C1 & MG972235 \\
C. curvisetus 2c & El6A2 & LC466961 \\
C. curvisetus 3 & newBB2 & MG972241 \\
C. curvisetus 3e & El4A2 & LC466962 \\
C. pseudocurvisetus & IRB & MG385841, V9 not included \\
C. pseudocurvisetus & Na13C4 & MG972304 \\
C. cf. tortissimus & Na18C4 & MG972275 \\
C. tortissimus & Na25A2 & MG972325 \\
\hline
\end{tabular}

Table 2 List of species abbreviations utilised in the present study.

\begin{tabular}{|c|c|c|c|}
\hline $\begin{array}{l}\text { Species } \\
\text { (this study) }\end{array}$ & $\begin{array}{l}\text { Abbreviation } \\
\text { (this study) }\end{array}$ & Corresponding species & $\begin{array}{l}\text { Reference for } \\
\text { the species }\end{array}$ \\
\hline C. sp. 1 & sp. 1 & C. curvisetus 1 & {$[39,52]$} \\
\hline C. sp. 2 & sp. 2 & C. curvisetus 2 & {$[39,52]$} \\
\hline C. sp. 3 & sp. 3 & C. curvisetus 3 & [39] \\
\hline C. sp. 4 & sp. 4 & C. curvisetus $2 \mathrm{c}$ & {$[53]$} \\
\hline C. sp. 5 & sp. 5 & C. curvisetus $3 \mathrm{e}$ & {$[53]$} \\
\hline C. sp. 6 & sp. 6 & C. pseudocurvisetus & {$[39,52]$} \\
\hline C. sp. 7 & sp. 7 & $\begin{array}{l}\text { C. curvisetus SKLMP } \\
\text { YG033 }\end{array}$ & $\begin{array}{l}\text { [GenBank } \\
\text { direct } \\
\text { submission] }\end{array}$ \\
\hline C. sp. 8 & sp. 8 & $\begin{array}{l}\text { Putative new species } \\
\text { (OSD dataset) }\end{array}$ & [This study] \\
\hline C. sp. 9 & sp. 9 & $\begin{array}{l}\text { Putative new species } \\
\text { (OSD dataset) }\end{array}$ & [This study] \\
\hline C. sp. 10 & sp. 10 & $\begin{array}{l}\text { Putative new species } \\
\text { (Tara dataset) }\end{array}$ & [This study] \\
\hline C. sp. 11 & sp. 11 & $\begin{array}{l}\text { Putative new species } \\
\text { (Tara dataset) }\end{array}$ & [This study] \\
\hline
\end{tabular}

(Table 1). All the ten 18S rRNA gene references included the V4 region as amplified by the primers used in OSD [36], modified from [55]), whereas two of them did not cover the V9 region as amplified by the Tara Oceans primers ([56]; see Table 1). To simplify the nomenclature of the species belonging to this complex (some genetically defined previously $[39,53]$, others identified in the present study) we indicated the taxa in the $C$. curvisetus complex as sp. 1-sp. 11 (Table 2). From the full-length 18S rRNA gene sequences we extracted the V4 and V9 regions, corresponding with the fragments amplified in OSD and Tara Oceans, respectively. None of the 'curvisetus' species shared identical V4 and V9 barcodes.

\section{Downloading and processing of metabarcode data}

The OSD dataset included 144 samples for the V4 region of the 18S rRNA gene (https://mb3is.megx.net/osd-files?pa th $=/ 2014 /$ datasets/workable) and 31 samples for the V9 region of the 18S rRNA gene (https://mb3is.megx.net/osdfiles?path $=\% 2 \mathrm{~F} 2014 \% 2 \mathrm{Fdatasets} \% 2 \mathrm{Fw}$ orkable $\% 2 \mathrm{Frdna}$ ).

From the V4-OSD workable fasta files, we generated a total fasta file with the unique haplotypes and a table containing the abundance of their reads at each site (Total OSD abundance table) using mothur v1.41.1 [57]. In this manuscript, we indicate with the term 'haplotype' a group of identical cleaned reads. The same procedure was done for OSD-V9 workable fasta files. The Tara Oceans V9 dataset was downloaded from https://doi.pangaea.de/10.1594/ PANGAEA.873277 and ENA (accession number: PRJEB9737; [58, 59]). We directly extracted the fasta file of haplotypes (unique cleaned reads) and the Total Tara Oceans abundance table from the downloaded file containing reads of Tara Oceans' 210 sites. We then generated a full V9 dataset including OSD-V9 and Tara Oceans data.

\section{Recovery of species from global metabarcoding datasets}

The V4 and V9 fragments of the ten references were used as queries for a local blastn BLAST [60] against OSD (V4) and OSD-V9 + Tara Oceans datasets, respectively, to extract haplotypes at $\geq 95 \%$ similarity. The strategy of using references of close outgroups and a relaxed similarity threshold (95\%) ensured inclusion of all haplotypes belonging to the $C$. curvisetus species complex, plus those of unknown species therein. The extracted metabarcode haplotypes were aligned with the ten references using MAFFT online [61] and a phylogenetic tree was built in FastTree v2.1.8 [62], using the GTR model. The resulting tree was visualised and modified in Archaeopteryx v0.9901 [63] to remove haplotypes resolving within outgroup clades (false-positives). This procedure was carried out separately for V4 and V9 fragments. The retained (validated) haplotypes were considered to belong to taxa in the $C$. curvisetus species complex. The abundance and distribution of V4 and V9 curvisetus haplotypes were extracted from the Total OSD and Tara Oceans abundance tables. At the end of the validation procedures, four files were generated, containing the validated OSD and OSD-V9 + Tara Oceans sequences in fasta format and the respective abundance tables (available on figshare, see 'Data availability' section).

\section{Phylogenetic haplotype network inference}

Phylogenetic haplotype networks were constructed using the statistical parsimony algorithm by [64] implemented in 
TCS network [65]. Networks were visualised in PopART v1.7 [66] including the information of read abundances for each haplotype. Each network was exported in nexus format and as table containing the list of sequence ID's (both reference and metabarcode haplotypes) grouped in each node in the network. Considering that the number of mismatches between nodes was normally distributed in both V4 and V9 networks (mean $(\mu) \pm$ standard deviation $(\sigma)$, median, and mode for V4: $1.14 \pm 0.60,1$, and 1 , and for V9: $1.03 \pm 0.49,1$, and 1 , respectively), we considered 2 mismatches $(\mu+2 \sigma)$, corresponding to the area describing the $95.46 \%$ of mismatch distribution, as threshold for errors and intra-specific variation. Based on these assumptions, we inferred species using the following criteria: (1) nodes without the reference and exhibiting $\leq 2$ mismatches with the node containing the reference were attributed to that taxon; (2) nodes without reference and with $>2$ mismatches with respect to the nodes with reference were considered as hypothetical new taxa if their read-abundance was $\geq 2$. After species inference, we took the representative sequence (the most abundant) of each delimited species and inferred a phylogenetic tree (for V4 and V9 regions) for a rapid and supported visualisation of phylogenetic relationships among taxa. Maximum Likelihood (ML) trees were inferred using IQ-TREE v1.6.8 [67] under the TN + F + G4 model for V4 and the $\mathrm{K} 2 \mathrm{P}+\mathrm{G} 4$ model for V9 (suggested by ModelFinder, [68]) and 1000 bootstrap replicates for both datasets. Sequences of $C$. tortissimus and $C$. cf. tortissimus were used as outgroup.

\section{Genetic divergence among species and variability within species}

To quantify the relatedness of each species in terms of distances, we calculated the net genetic distance between pairs of species as implemented in MEGA6 [69]. We used the Jukes and Cantor model of sequence evolution [70] to calculate the distances across all metabarcode haplotypes of each species, which best fitted our data. We also calculated, using the same model, the minimum, maximum and average evolutionary divergence of sequences within nodes (the number of base substitutions per site from averaging over all sequence pairs within each group) using MEGA6 [69]. The presence of barcoding gap in the inferred species was explored. The barcoding gap was considered to occur if the maximum distance among sequences within species was lower than the minimum distance among sequences between species [71].

\section{Global phylogeography of taxa belonging to the C. curvisetus species complex}

The distribution of the inferred species of the C. curvisetus complex was mapped over the world's oceans.
First, from the abundance tables previously generated (see 'Data availability' section), we summed the abundances of the haplotypes belonging to the same inferred species. Then, data were normalised to the total number of reads for each sample and reported as percentage. Finally, we plotted the transformed abundance of each inferred species in Longhurst's provinces in the form of heatmaps. For heatmap generation, we used the R [72] working packages phyloseq [73] and ggplot2 [74]. We also plotted the occurrence of each species over the sample stations on a world map using the packages maps [75] and ggplot 2 .

\section{Results}

\section{Validation of candidate haplotypes in the $C$. curvisetus species complex}

BLAST analysis of the ten reference V4 rRNA gene sequences against the OSD-V4 data retrieved 4223 reads corresponding to 1428 unique (non-redundant) haplotypes. The phylogenetic tree-approach resulted in the validation of 1232 of these haplotypes (3804 reads) as members of the C. curvisetus species complex (files V4_OSD_curvi_validated.fasta and OSD_plus_OSD-V9_Tara_abundance_tables. xlsx available on figshare, see Data availability). BLAST analysis of the eight reference V9 rRNA gene sequences against the OSD-V9 and Tara Oceans data returned 2247 haplotypes (856967 reads in Tara Oceans and 194 in OSDV9). After validation, 772 haplotypes (68210 reads in Tara Oceans and 192 in OSD-V9) were found to belong to the complex (files V9_TARA_LW_curvi_validated.fasta and OSD_plus_OSD-V9_Tara_abundance_tables.xlsx available on figshare, see 'Data availability' section). Reads of validated haplotypes were found in 60 out of 144 OSD sampling sites $(41.7 \%)$ and 117 out of 210 Tara Oceans stations (55.7\%) (Fig. 2, Supplementary Table 1).

\section{Phylogenetic haplotype networks}

The haplotype network based on the OSD dataset (V4 region of the $18 \mathrm{~S}$ rRNA gene) contained seven nodes assigned to known species in the $C$. curvisetus species complex plus two without a reference (Fig. 3a). Most of the metabarcodes were assigned to sp. 1, 2, 3, 6 and 7 (Fig. 3a). Only one haplotype was recovered for the reference of sp. 5 and, likewise, only one haplotype for that of sp. 4. Many haplotypes clustered into two closely related nodes (spp. 8 and 9) lacking references (Fig. 3a). Moreover, sp. 3 is more closely related to sp. 6 (C. pseudocurvisetus) than to the other 'C. curvisetus' species; sp. 5 (Red Sea) is closely related to sp. 6 and distantly to sp. 1. This latter node is 
Fig. 2 Occurrence of taxa belonging to the $C$. curvisetus species complex. a OSD data; b Tara Oceans data. Light blue dots refer to occurrence in OSD data (V4 + V9 regions of the 18S rRNA gene), whilst orange dots, in Tara Oceans data. Grey triangles indicate absence in the molecular data from the respective sampling site. a)

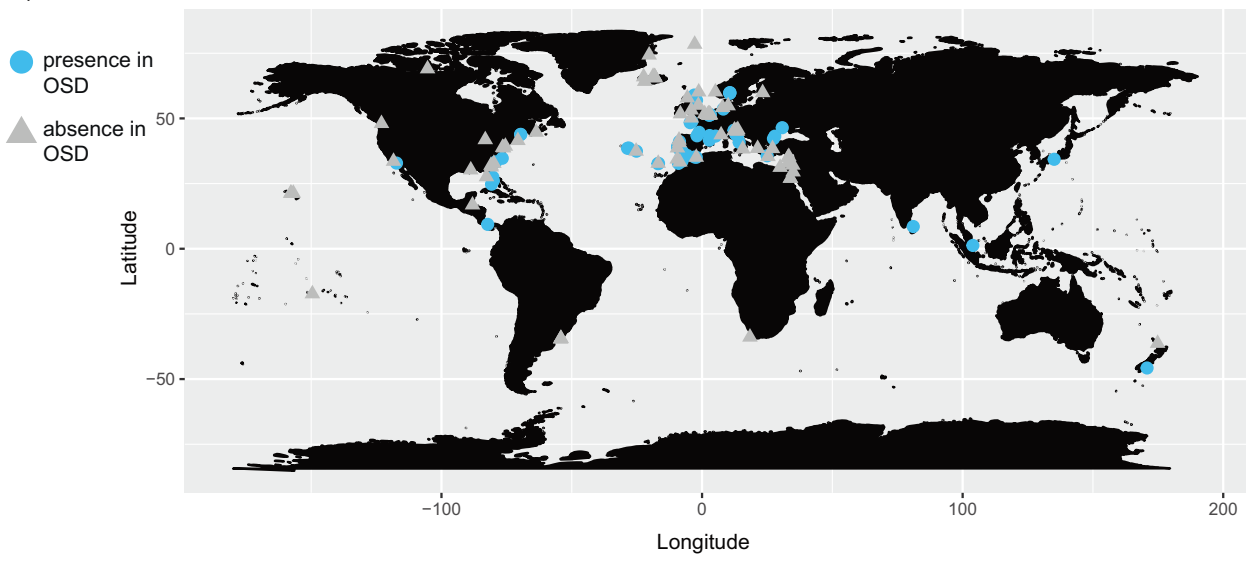

b)

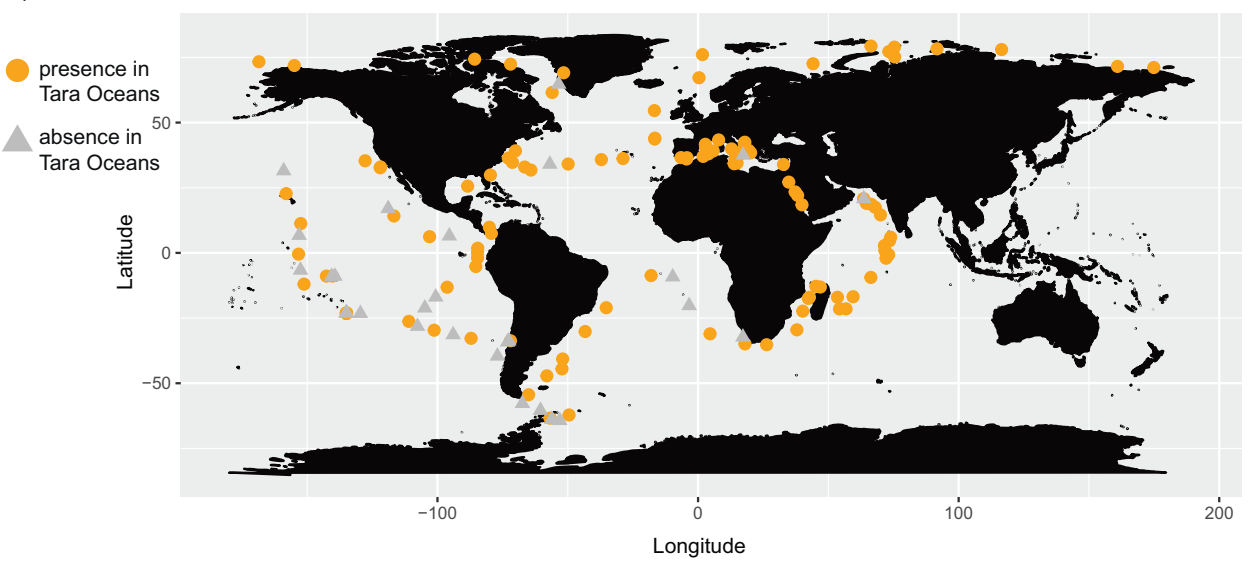

separated by eight mismatches from the reference of $\mathrm{sp} .7$ from Hong Kong.

The haplotype network based on the Tara Oceans dataset (V9 region of the $18 \mathrm{~S}$ rRNA gene) contained six nodes assigned to a known species plus two without a reference (Fig. 3b). Most of the haplotypes were assigned to sp. 2; and many to spp. 3 and 5, whereas all the other species were less abundant. The node of sp. 3 was close but clearly separated from a peripheral node with a large number of reads. The same was observed for sp. 5. These peripheral nodes were treated as distinct species (spp. 10 and 11, respectively). Nodes containing the V9 reference sequences of two strains from the Red Sea (spp. 4 and 5) showed high abundance in the Tara Oceans dataset.

The V4 regions of the $18 \mathrm{~S}$ rRNA gene sequences of spp. 8 and 9, and the V9 regions of the 18S rRNA gene sequences of spp. 10 and 11 were blasted against NCBI GenBank with the aim of retrieving complete 18S rRNA gene sequences showing exact match with the V4 of sp. 8 or 9 as well as the V9 of sp. 10 or 11 . Such a finding would demonstrate that nodes in the V4- and V9 networks represent the same species. However, such a connection could not be made because none of these sequences obtained an exact hit. The representative sequences (dominant haplotypes) for these four putative new species are available in GenBank (see 'Data availability' section). An alignment of the representative V4 and V9 sequences of each species with sequence signatures is provided in Supplementary Information (Supplementary Fig. 1).

In the network inferred from the V4 region of the $18 \mathrm{~S}$ rRNA gene (Fig. 3a), the group encompassing spp. 3, 5 and 6 was recovered midway between sp. 1 on one side and spp. 2, 8 and 9 on the other side. Likewise, sp. 4 was recovered in between sp. 2 and spp. 8 and 9. The main branches connecting the nodes showed little reticulation, suggesting reduced gene flow or none at all. The link between sp. 8 and sp. 9 was reticulated, suggestive for gene flow between the two. In the network inferred from the V9 region of the $18 \mathrm{~S}$ rRNA gene (Fig. 3b), the node attributed to sp. 1 was like a pivot with three branches: one branch with sp. 3, another branch with spp. 2 and 4, and a third branch with spp. 5 and 6 . These three branches were devoid of intricate reticulations, suggesting paucity or absence of gene flow.

The ML tree inferred using the V4 representative sequences (the most abundant) of each newly identified putative species plus the references confirmed that the taxa without reference barcodes (spp. 8 and 9) are members of the $C$. curvisetus species complex and likely constitute at 
Fig. 3 TCS haplotype networks for the $\boldsymbol{C}$. curvisetus species complex. a OSD data; b OSD-V9 + Tara Oceans data. The size of the nodes refers to the abundance of the reads. Asterisk (*) indicates nodes without a reference barcode corresponding to putative new species. Numbers in bold indicate the number of mutations. Edges with the same number of mutations are marked with a straight line.

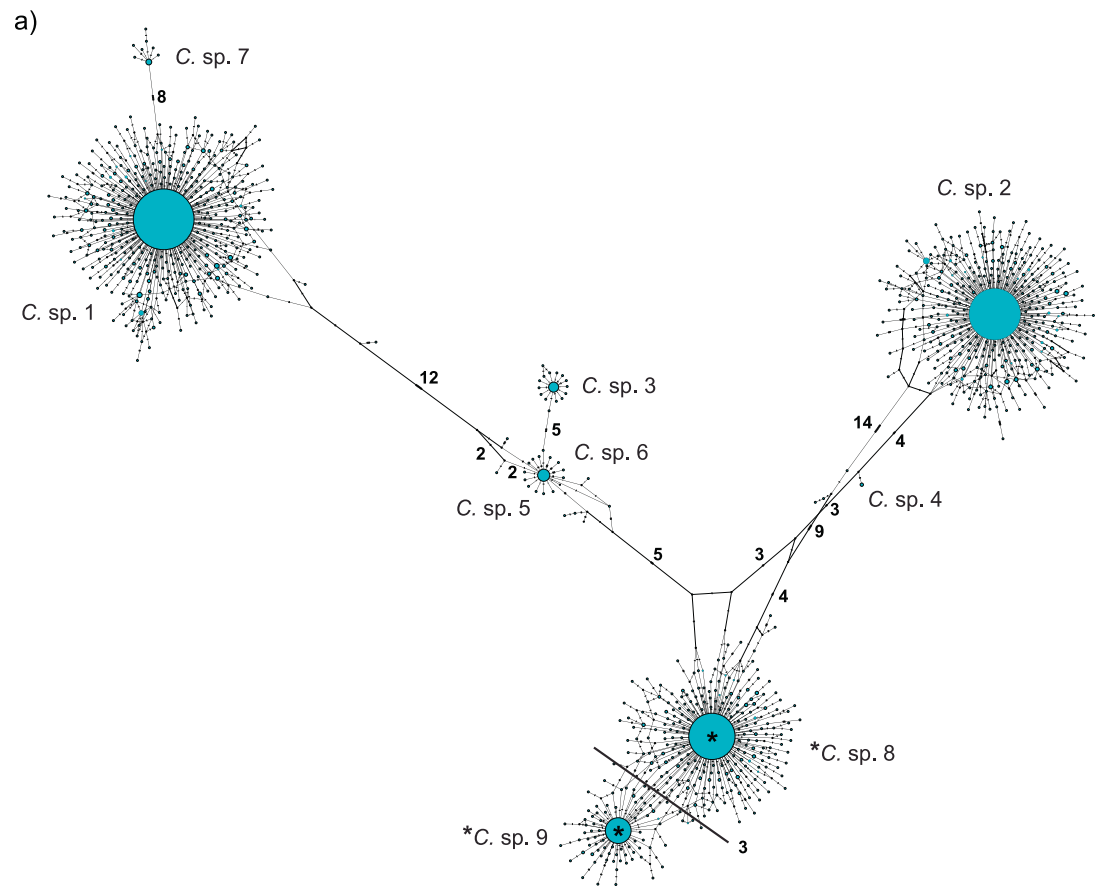

b)

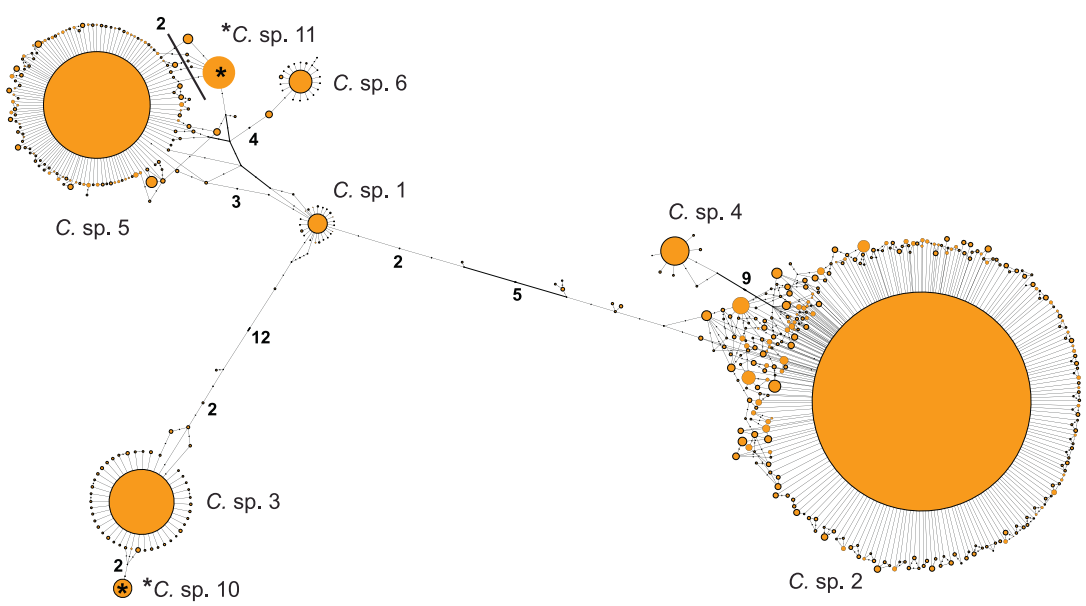

least one new species (Supplementary Fig. 2a). The two taxa are closely related and share a common ancestor with sp. 2 (Supplementary Fig. 2a). In this tree, the clade with spp. 1 and 7 was the first to branch off. Instead, in the V9 tree (Supplementary Fig. 2b) the clade with spp. 2 and 4 was sister to a polytomy with the remainder of the ingroup references plus spp. 10 and 11 . The haplotype of sp. 10 was recovered as close sister of $\mathrm{sp} .3$.

\section{Genetic differentiation and variability}

Pairwise genetic distances among the inferred species differed between the V4 and V9 regions of the rRNA gene, but the proportions were comparable. For V4, the lowest interspecific genetic distances were between spp. 5 and 6 (0.007) and between spp. 8 and 9 (0.008, Supplementary Table 2a), whilst the highest values were observed between spp. 1 and $2(0.107)$ and between spp. 2 and 7 (0.105) (Supplementary Table 2a). For V9, inter-specific distances ranged from 0.368 (between spp. 3 and 4) to 0.022 (between spp. 5 and 11) (Supplementary Table 2b). The highest intra-specific distance for the V4 and the V9 regions (0.105 and 0.049 , respectively) was higher than their minimum inter-specific distance (0.007 and 0.022 , respectively). Therefore, no threshold value could be established to distinguish between inter- and intra-specific variability (barcoding gap). Within each species, the mean evolutionary divergence over sequence pairs ranged from 0.000 (sp. 4) to 0.055 (sp. 5) for V4 region and from 0.000 (sp. 3) to 0.017 (sp. 2) for V9 (Supplementary Table 3). 
Fig. 4 Heatmaps showing the abundance of $C$. curvisetus spp. in each Longhurst's province. a OSD data; b OSDV9 + Tara Oceans data. Data were normalised to the total number of reads for each sample and reported as percentage. Species on the left are ordered according to phylogenetic closeness in the respective networks. For the meaning of the provinces, see ref. [54]. a)

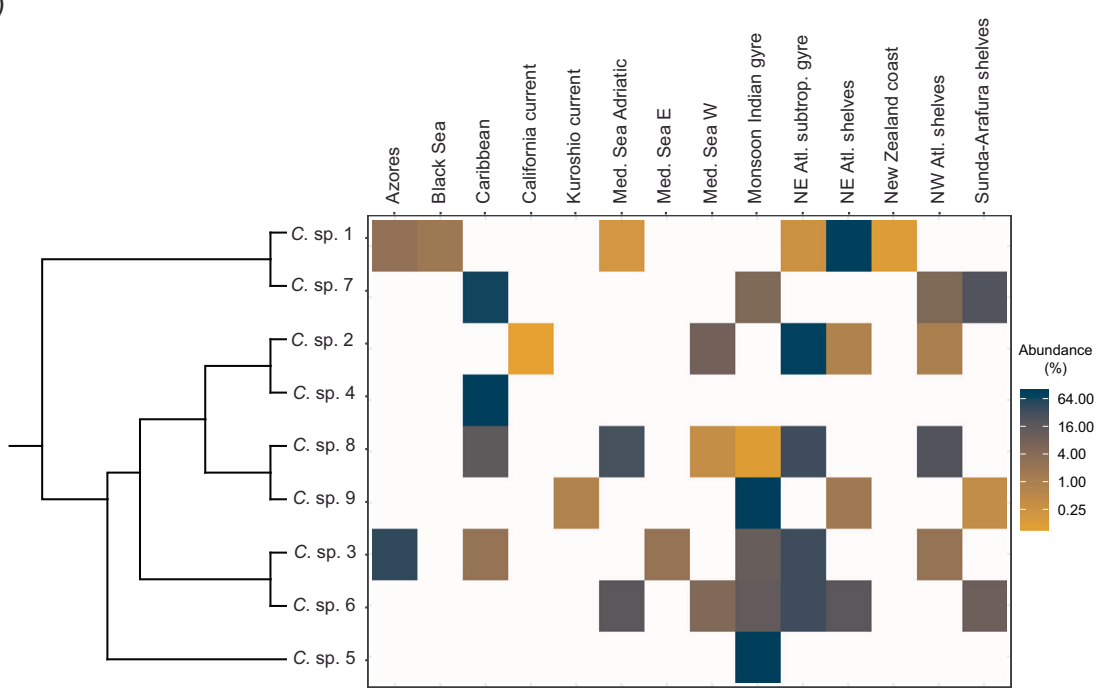

b)

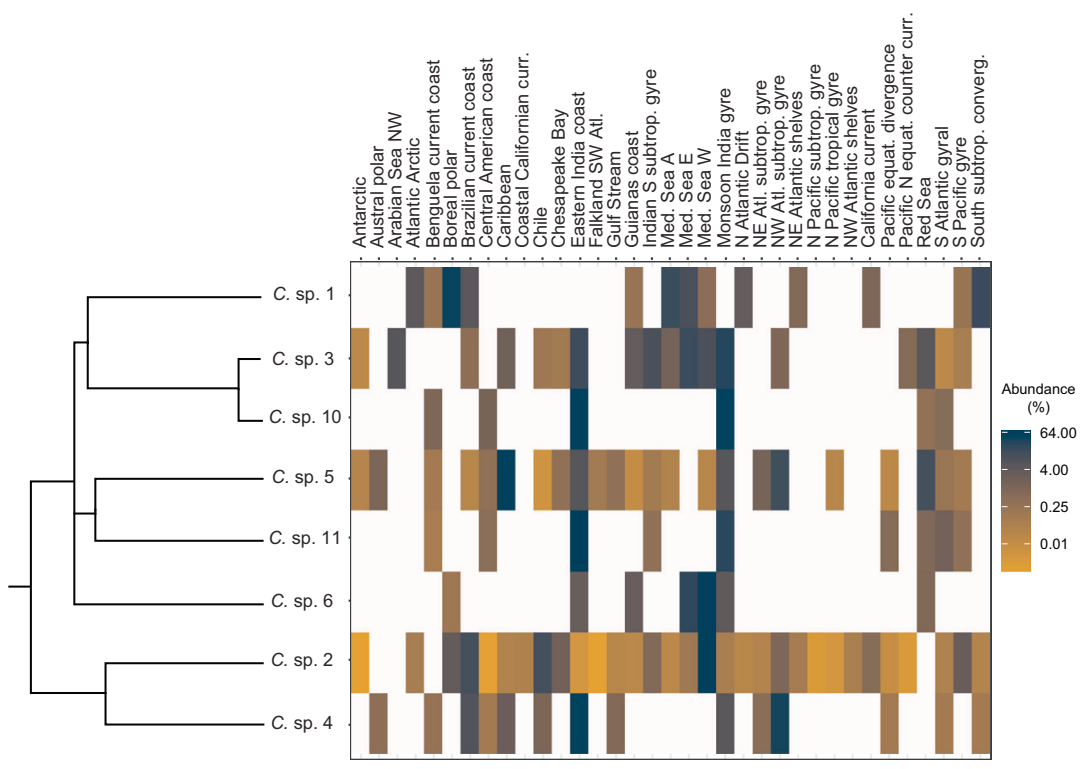

\section{Global distribution of taxa belonging to the $C$. curvisetus species complex}

Plots of occurrences gathered from OSD and Tara Oceans metabarcoding data revealed that the species complex is cosmopolitan, occurring in samples in both coastal and open ocean waters at all latitudes in the northern to southern hemispheres (Fig. 2a, b). Yet, the inferred species showed slightly to markedly more restricted distribution patterns (Fig. 4a, b; Supplementary Fig. 3); sp. 1 was found, often abundantly, in the Atlantic, Arctic and temperate provinces, whilst sp. 2 was observed there as well but also all over the tropics and subtropics. Instead, spp. 3, 4 and 5 showed a predominantly warm-temperate to tropical distribution, though the latter two were encountered also near the Antarctic peninsula. Notably, spp. 10 and 11 were more strictly tropical (V9, observable only in Tara Oceans data). The remaining species were encountered less frequently, often at sample sites far apart, e.g. sp. 6 in southern Europe, the Red Sea and scattered along the coasts of the Indian Ocean; sp. 7 in Florida and Singapore; sp. 8 only on the US-East Coast, Panama and the Mediterranean and sp. 9 at a few sites in the tropical Indian Ocean and in Japan (the latter three species observable only in V4, OSD data).

For those species potentially detectable in both datasets (reference sequences including both the V4 and V9), spp. 1 and 6 were well-represented at the OSD sample sites, at least in Europe, but infrequent at the Tara Oceans sites; sp. 2 was observed in both OSD and Tara Oceans sites; and spp. 3, 4 and 5 occurred at many Tara Oceans sites but were rare in the OSD data. Several closely related pairs of species in the V4-tree exhibited distinct distribution ranges (spp. 1 
and 7; spp. 2 and 4; spp. 3 and 6; spp. 8 and 9; see Fig. 4a; Supplementary Fig. 2a), and the same was observed between close relatives in the V9 tree (spp. 3 and 10; spp. 5 and 11; spp. 2 and 4; see Fig. 4b; Supplementary Fig. 2b).

\section{Discussion}

\section{Phylogenetic relationships among taxa belonging to the $C$. curvisetus species complex}

Haplotype networks enable delineation of taxa within the $C$. curvisetus species complex and visualisation of the relationships among these taxa. Despite the fact that the global metabarcoding datasets here analysed are different in terms of gene region sequenced and sampling coverage, we retrieve the same number of taxa, including newly inferred ones. This suggests that the molecular information contained in these datasets allows an exhaustive exploration of the complex. In terms of phylogenetic relationships, haplotype networks display relationships better than previously published phylogenetic trees. Indeed, in the trees inferred from the V4- and V9 regions of the 18S rRNA gene [39], as well as in the multigene phylogeny by [53], relationships among the members of this complex are poorly resolved, especially in the tree inferred from the V9 region. The fact that adding more reference barcodes and DNA markers to the phylogenies [53] did not result in any significant improvements in resolution suggests that the approach used to resolve relationships is more important than the number and type of markers analysed. Phylogenies visualise speciation events as dichotomies, whereas haplotype networks can model evolution in a reticulated manner, best fitting cases of recent divergence as may occur in species complexes.

Slight differences in relationships identified in the networks of the V4 and V9 regions of the 18S rRNA gene are likely due to different length of the regions ( 384 and $~ 105$ bp, respectively) and are also observed in the V4 and V9 phylogenetic trees in [39]. Furthermore, the reticulations within the networks suggest a weak, but nonetheless existing gene flow between inferred species. The absence of a barcoding gap corroborates that signal, suggesting that the genetic barriers among some members of the complex are incomplete.

The V4 and V9 networks allow proposing hypotheses on putative new species or emerging populations, as also confirmed in the trees obtained using the reference barcodes of curvisetus species and the representative sequences of unassigned nodes. Such inference of taxa from metabarcode haplotypes is just the first step of the process; the next step is to try to isolate the target organism in order to link the anonymous sequence to the morphology of the specific taxon. This approach, called 'reverse taxonomy' [76] was applied previously in other marine protists and metazoans $[14,77]$. In the case of metabarcoding data, the validation of anonymous sequences through isolation of the target organism is supported by abundance tables, which contain information of occurrence, abundance and date for each sampled locality.

\section{Considerations on Sanger vs. metabarcoding sequencing data}

In this work, we have used the accepted barcode for protists (the V4 region of the rRNA gene, [26]) and the V9 region of the rRNA gene to study a cryptic species complex. Instead of a classical, Sanger-based approach of a multitude of geographic strains, we have used metabarcoding datasets (OSD and Tara Oceans), to take advantage of the data available for many sampling localities across the globe. It would have been logistically next to impossible to establish monoclonal strains from all of these sites. As consequence of this choice, we had to work with thousands of sequences. Indeed, differently from a Sanger sequencing approach that provides a single sequence as output (a consensus of all the amplified products), HTS techniques sequence individual molecules. Furthermore, since the $18 \mathrm{~S}$ gene occurs in hundreds to thousands of copies within the genome, and sometime on multiple chromosomes [78], the number of sequences to handle was even larger. Such rRNA gene copies are expected to be homogenised by concerted evolution over time, but empirical studies suggest that this process is not perfect and multiple, polymorphic copies can persist within the genome [79]. When using environmental samples, 18S rRNA gene copies from different cistrons, chromosomes and individuals are mixed together, precluding the distinction between intra- and inter-specific variability. Using the network approach and simple criteria to assign sequences to a species, we have demonstrated that this is not an issue. All these sequences resulting from the apparent failure of concerted evolution to achieve complete homogenisation, from geographic variability, from PCR and sequencing errors are arranged around the main node in which the 'dominant haplotype' is located. All these, i.e. the dominant haplotype and its surrounding peripheral haplotypes contribute to the definition of the species' overall genetic variation for this marker region. This aspect of concerted evolution suggested by metabarcoding data, as well as the fact that the most abundant haplotype for a specific taxon corresponds to its reference barcode obtained with Sanger sequencing, has been demonstrated recently by [80] in a temporal dataset of Chaetocerotaceae at local scale. In this context, we show that the use of a multi-copy gene is not a disadvantage, but instead, that all these copies contribute to the evaluation of inter- and intra-species variation. 


\section{Eco-evo considerations of the $C$. curvisetus species complex}

C. curvisetus was originally described from the Kattegat [81] and reported by [82] as a common inhabitant of the Atlantic Ocean and the Baltic Sea, with peaks of abundance in summer and autumn. Hasle and Syvertsen [51] indicated it as a cosmopolitan species mainly found in temperate and warm waters and this was also confirmed by [83]. In Chinese waters, the species has been associated with harmful algal blooms [84, 85], although no production of toxins is known to date. Instead, $C$. pseudocurvisetus is considered by [51] as an inhabitant of warm waters. This finding was partially confirmed by [83], in which the species was found not only in the Mediterranean Sea, the nearby Atlantic Ocean and the Indian Ocean, but also in the North Sea, the latter being quite balmy in high summer.

In general, results of our analysis using OSD and Tara Oceans dataset indicate that the $C$. curvisetus complex is cosmopolitan. Nonetheless, some species show preferences for particular environmental conditions. Furthermore, closely related species often exhibit contrasting geographic distribution patterns mainly related to temperature preferences, especially if they are clearly separated in the network (no reticulation; e.g. spp. 1 and 7). Instead, species connected by reticulate patterns probably still experience gene flow (e.g. spp. 8 and 9) and exhibit more comparable distribution patterns. Despite the fact that the partitioning of ocean regions in Longhurst's provinces takes into account several biogeochemical parameters, Richter et al. [86] have shown that temperature alone is more correlated to the distribution of larger plankton species (as diatoms) than other environmental parameters.

Other studies involving cryptic species in marine protists have shown similar results. In the genus Skeletonema, widely distributed $S$. costatum sensu lato consists of a species complex [5, 87]. Several of its species appear to be widely distributed as well, but within broad climatological boundaries (cool-temperate $S$. japonicum; temperate to tropical S. tropicum) whereas others such as $S$. grethae seem to be regional and absent in climatologically comparable regions [13]. More in general, Hasle [88] already noticed that morphologically closely related diatom species are often found in different biogeographic regions. In Leptocylindrus, most species were found to be widespread in coastal waters whereas L. minimus was restricted to cold waters of the Northern Hemisphere [14, 89]. Similar results were also reported for cryptic species complexes within green algae [90-93]. Our results and the information available in the aforementioned studies indicate that ecological traits are as reliable as phylogenetic data for the circumscription of taxa within a cryptic species complex, and provide a strong support for the formulation of primary species hypotheses.
According to the 'everything is everywhere' hypothesis [94], most microbes form populations large enough to migrate efficiently and accumulate mutations that could be beneficial in particular environments [95]. Speciation in the microbial world is therefore expected to involve selection rather than random drift or geographical separation [95]. Diatoms, for example, are believed to exhibit high intraspecific variability, which would be key for their adaptation to different environments [96]. It is possible that different strains of a species already possess beneficial mutations allowing them to adapt to different environments using such intra-specific variability [96]. Once a different environment is reached, some strains would be favoured by natural selection and, over time, accumulate other mutations that will finally differentiate them from the parental population, leading to speciation. In this context, the adaptation to different environments would be the factor triggering speciation in diatoms. Based on the results of this study and data for other protists we conclude that ecological differentiation is likely to facilitate speciation both in allopatric [93, 97] and sympatric [98-100] conditions.

In conclusion, this work shows that the study of cryptic species complexes in marine protists can benefit from the combination of evolutionary approaches and HTS data. First, molecular data from global metabarcoding datasets provide an exhaustive picture of the genetic variability of the cryptic species complex under investigation. Second, the use of phylogenetic networks over trees allows a better visualisation of relationships among closely related taxa, especially when using metabarcoding data from multi-copy genes, where there is no a priori definition of intra- and inter-specific genetic boundaries. Third, the large spatial coverage, including sampling points from different biogeographic regions across world's oceans, allows the integration of ecological traits in the delimitation of cryptic species. Taken together, all these analyses provide an ecoevolutionary framework for systematic biology assessments of cryptic species.

\section{Data availability}

The fasta reference sequences of the putative new species here identified are available on GenBank at the following accession numbers: MW168796-MW168799. The scripts and input files for generating phylogenetic networks, heatmaps and distribution maps are available on figshare at URL: https://doi.org/10.6084/m9.figshare.13150400. Other Supplementary Information is available for download on the ISME website.

Funding WHCFK acknowledges funding from H2020 RI Cluster project EMBRIC (GA-654008) and FP7 project ASSEMBLE (GA227799). DDL was supported by a Ph.D. fellowship funded by the 
Stazione Zoologica Anton Dohrn of Naples (The Open UniversityStazione Zoologica Anton Dohrn Ph.D. Programme).

\section{Compliance with ethical standards}

Conflict of interest The authors declare that they have no conflict of interest.

Publisher's note Springer Nature remains neutral with regard to jurisdictional claims in published maps and institutional affiliations.

Open Access This article is licensed under a Creative Commons Attribution 4.0 International License, which permits use, sharing, adaptation, distribution and reproduction in any medium or format, as long as you give appropriate credit to the original author(s) and the source, provide a link to the Creative Commons license, and indicate if changes were made. The images or other third party material in this article are included in the article's Creative Commons license, unless indicated otherwise in a credit line to the material. If material is not included in the article's Creative Commons license and your intended use is not permitted by statutory regulation or exceeds the permitted use, you will need to obtain permission directly from the copyright holder. To view a copy of this license, visit http://creativecommons. org/licenses/by/4.0/.

\section{References}

1. Mayr E. Populations, species, and evolution: an abridgment of animal species and evolution. Cambridge: Belknap Press of Harvard University Press; 1970.

2. Bickford D, Lohman DJ, Sodhi NS, Ng PKL, Meier R, Winker $\mathrm{K}$, et al. Cryptic species as a window on diversity and conservation. Trends Ecol Evol. 2007;22:148-55.

3. Fišer C, Robinson CT, Malard F. Cryptic species as a window into the paradigm shift of the species concept. Mol Ecol. 2018;27:613-35.

4. Struck TH, Feder JL, Bendiksby M, Birkeland S, Cerca J, Gusarov VI, et al. Finding evolutionary processes hidden in cryptic species. Trends Ecol Evol. 2018;33:153-63.

5. Sarno D, Kooistra WHCF, Medlin LK, Percopo I, Zingone A. Diversity in the genus Skeletonema (Bacillariophyceae). II. An assessment of the taxonomy of $S$. costatum-like species with the description of four new species. J Phycol. 2005;41:151-76.

6. Gaonkar CC, Kooistra WHCF, Lange CB, Montresor M, Sarno D. Two new species in the Chaetoceros socialis complex (Bacillariophyta): C. sporotruncatus and C. dichatoensis, and characterization of its relatives. J Phycol. 2017;53:889-907.

7. Li Y, Boonprakob A, Gaonkar CC, Kooistra WHCF, Lange CB, Hernández-Becerril D, et al. Diversity in the globally distributed diatom genus Chaetoceros (Bacillariophyceae): three new species from warm-temperate waters. PLoS ONE. 2017;12: e0168887.

8. Finlay BJ, Clarke KJ. Ubiquitous dispersal of microbial species. Nature. 1999;400:828.

9. Finlay BJ, Fenchel T. Divergent perspectives on protist species richness. Protist. 1999;150:229-33.

10. Fenchel T, Finlay BJ. The ubiquity of small species: patterns of local and global diversity. Bioscience. 2004;54:777.

11. Fenchel T. Cosmopolitan microbes and their 'cryptic' species. Aquat Microb Ecol. 2005;41:49-54.

12. Miglietta MP, Faucci A, Santini F. Speciation in the sea: overview of the symposium and discussion of future directions. Integr Comp Biol. 2011;51:449-55.
13. Kooistra WHCF, Sarno D, Balzano S, Gu H, Andersen RA, Zingone A. Global diversity and biogeography of Skeletonema species (Bacillariophyta). Protist. 2008;159:177-93.

14. Nanjappa D, Audic S, Romac S, Kooistra WHCF, Zingone A. Assessment of species diversity and distribution of an ancient diatom lineage using a DNA metabarcoding approach. PLoS ONE. 2014;9:e103810.

15. Kaczmarska I, Mather L, Luddington IA, Muise F, Ehrman JM. Cryptic diversity in a cosmopolitan diatom known as Asterionellopsis glacialis (Fragilariaceae): Implications for ecology, biogeography, and taxonomy. Am J Bot. 2014;101:267-86.

16. Zhao Y, Yi Z, Gentekaki E, Zhan A, Al-Farraj SA, Song W. Utility of combining morphological characters, nuclear and mitochondrial genes: An attempt to resolve the conflicts of species identification for ciliated protists. Mol Phylogenet Evol. 2016;94:718-29.

17. Weiner A, Aurahs R, Kurasawa A, Kitazato H, Kucera M. Vertical niche partitioning between cryptic sibling species of a cosmopolitan marine planktonic protist. Mol Ecol. 2012;21:4063-73.

18. Lamari N, Ruggiero MV, d'Ippolito G, Kooistra WHCF, Fontana A, Montresor M. Specificity of lipoxygenase pathways supports species delineation in the marine diatom genus Pseudonitzschia. PLoS ONE. 2013;8:e73281.

19. Škaloud P, Friedl T, Hallmann C, Beck A, Dal Grande F. Taxonomic revision and species delimitation of coccoid green algae currently assigned to the genus Dictyochloropsis (Trebouxiophyceae, Chlorophyta). J Phycol. 2016;52:599-617.

20. de Jesus PB, Costa AL, de Castro Nunes JM, Manghisi A, Genovese G, Morabito M, et al. Species delimitation methods reveal cryptic diversity in the Hypnea cornuta complex (Cystocloniaceae, Rhodophyta). Eur J Phycol. 2019;54:135-53.

21. Díaz-Tapia P, Ly M, Verbruggen H. Extensive cryptic diversity in the widely distributed Polysiphonia scopulorum (Rhodomelaceae, Rhodophyta): molecular species delimitation and morphometric analyses. Mol Phylogenet Evol. 2020;152:106909.

22. Huson DH, Rupp R, Scornavacca C. Phylogenetic networks. Cambridge: Cambridge University Press; 2009.

23. Huson DH, Bryant D. Application of phylogenetic networks in evolutionary studies. Mol Biol Evol. 2006;23:254-67.

24. Solís-Lemus C, Yang M, Ané C. Inconsistency of species tree methods under gene flow. Syst Biol. 2016;65:843-51.

25. Deiner K, Bik HM, Mächler E, Seymour M, Lacoursière-Roussel A, Altermatt $\mathrm{F}$, et al. Environmental DNA metabarcoding: Transforming how we survey animal and plant communities. Mol Ecol. 2017;26:5872-95.

26. Pawlowski J, Audic S, Adl S, Bass D, Belbahri L, Berney C, et al. CBOL protist working group: barcoding eukaryotic richness beyond the animal, plant, and fungal kingdoms. PLoS Biol. 2012;10:e1001419.

27. Trobajo R, Mann DG, Clavero E, Evans KM, Vanormelingen P, McGregor RC. The use of partial cox1, rbcL and LSU rDNA sequences for phylogenetics and species identification within the Nitzschia palea species complex (Bacillariophyceae). Eur J Phycol. 2010;45:413-25.

28. Decelle J, Suzuki N, Mahé F, De Vargas C, Not F. Molecular phylogeny and morphological evolution of the acantharia (Radiolaria). Protist. 2012;163:435-50.

29. Stoeck T, Przybos E, Dunthorn M. The D1-D2 region of the large subunit ribosomal DNA as barcode for ciliates. Mol Ecol Resour. 2014;14:458-68.

30. Moniz MBJ, Kaczmarska I. Barcoding of diatoms: nuclear encoded ITS revisited. Protist. 2010;161:7-34.

31. Gile GH, Stern RF, James ER, Keeling PJ. DNA barcoding of chlorarachniophytes using nucleomorph ITS sequences. J Phycol. 2010;46:743-50. 
32. Stern RF, Andersen RA, Jameson I, Küpper FC, Coffroth M-A, Vaulot D, et al. Evaluating the ribosomal internal transcribed spacer (ITS) as a candidate dinoflagellate barcode marker. PLoS ONE. 2012;7:e42780.

33. Saunders GW. Applying DNA barcoding to red macroalgae: a preliminary appraisal holds promise for future applications. Philos Trans R Soc B Biol Sci. 2005;360:1879-88.

34. MacGillivary ML, Kaczmarska I. Survey of the efficacy of a short fragment of the rbcL gene as a supplemental DNA barcode for diatoms. J Eukaryot Microbiol. 2011;58:529-36.

35. Zimmermann J, Jahn R, Gemeinholzer B. Barcoding diatoms: evaluation of the V4 subregion on the 18S rRNA gene, including new primers and protocols. Org Divers Evol. 2011;11:173-92.

36. Piredda R, Tomasino MP, D’Erchia AM, Manzari C, Pesole G, Montresor M, et al. Diversity and temporal patterns of planktonic protist assemblages at a Mediterranean Long Term Ecological Research site. FEMS Microbiol Ecol. 2016;93:fiw200.

37. Pawlowski J, Lecroq B. Short rDNA barcodes for species identification in foraminifera. $\mathrm{J}$ Eukaryot Microbiol. 2010;57:197-205.

38. Mordret S, Piredda R, Vaulot D, Montresor M. Kooistra WHCF, Sarno D. dinoref: a curated dinoflagellate (Dinophyceae) reference database for the 18S rRNA gene. Mol Ecol Resour. 2018;18:974-87.

39. Gaonkar CC, Piredda R, Minucci C, Mann DG, Montresor M, Sarno D, et al. Annotated $18 \mathrm{~S}$ and $28 \mathrm{~S}$ rDNA reference sequences of taxa in the planktonic diatom family Chaetocerotaceae. PLoS ONE. 2018;13:e0208929.

40. Balzano S, Percopo I, Siano R, Gourvil P, Chanoine M, Marie D, et al. Morphological and genetic diversity of Beaufort Sea diatoms with high contributions from the Chaetoceros neogracilis species complex. J Phycol. 2017;53:161-87.

41. Kopf A, Bicak M, Kottmann R, Schnetzer J, Kostadinov I, Lehmann K, et al. The ocean sampling day consortium. Gigascience. 2015;4. https://doi.org/10.1186/s13742-015-0066-5.

42. Pesant S, Not F, Picheral M, Kandels-Lewis S, Le Bescot N, Gorsky G, et al. Open science resources for the discovery and analysis of Tara Oceans data. Sci Data. 2015;2:150023.

43. Yau S, Lopes dos Santos A, Eikrem W, Gérikas Ribeiro C, Gourvil P, Balzano S, et al. Mantoniella beaufortii and Mantoniella baffinensis sp. nov. (Mamiellales, Mamiellophyceae), two new green algal species from the high arctic. J Phycol. 2020;56:37-51.

44. Lopes Dos Santos A, Gourvil P, Tragin M, Noël M-H, Decelle J, Romac S, et al. Diversity and oceanic distribution of prasinophytes clade VII, the dominant group of green algae in oceanic waters. ISME J. 2017;11:512-28.

45. Kuwata A, Yamada K, Ichinomiya M, Yoshikawa S, Tragin M, Vaulot D, et al. Bolidophyceae, a sister picoplanktonic group of diatoms-a review. Front Mar Sci. 2018;5:370.

46. Segawa T, Matsuzaki R, Takeuchi N, Akiyoshi A, Navarro F, Sugiyama $\mathrm{S}$, et al. Bipolar dispersal of red-snow algae. Nat Commun. 2018;9:1-8.

47. Ichinomiya M, Dos Santos AL, Gourvil P, Yoshikawa S, Kamiya M, Ohki K, et al. Diversity and oceanic distribution of the Parmales (Bolidophyceae), a picoplanktonic group closely related to diatoms. ISME J. 2016;10:2419-34.

48. Tragin M, Vaulot D. Novel diversity within marine Mamiellophyceae (Chlorophyta) unveiled by metabarcoding. Sci Rep. 2019;9:1-14.

49. Morard R, Vollmar NM, Greco M, Kucera M. Unassigned diversity of planktonic foraminifera from environmental sequencing revealed as known but neglected species. PLoS ONE. 2019;14:e0213936.
50. Pinseel E, Janssens SB, Verleyen E, Vanormelingen P, Kohler TJ, Biersma EM, et al. Global radiation in a rare biosphere soil diatom. Nat Commun. 2020;11:1-12.

51. Hasle GR, Syvertsen EE. Marine diatoms. In: Tomas CR, editor. Identifying marine phytoplankton. San Diego: Academic Press; 1997. pp 5-385.

52. Kooistra WHCF, Sarno D, Hernández-Becerril DU, Assmy P, Di Prisco C, Montresor M. Comparative molecular and morphological phylogenetic analyses of taxa in the Chaetocerotaceae (Bacillariophyta). Phycologia. 2010;49:471-500.

53. De Luca D, Sarno D, Piredda R, Kooistra WHCF. A multigene phylogeny to infer the evolutionary history of Chaetocerotaceae (Bacillariophyta). Mol Phylogenet Evol. 2019;140:106575.

54. Longhurst AR. Toward and ecological geography of the sea. In: Longhurst AR, editor. Ecological geography of the sea. 2nd ed. Cambridge: Academic Press; 2007. pp 1-17.

55. Stoeck T, Bass D, Nebel M, Christen R, Jones MDM, Breiner H$\mathrm{W}$, et al. Multiple marker parallel tag environmental DNA sequencing reveals a highly complex eukaryotic community in marine anoxic water. Mol Ecol. 2010;19:21-31.

56. Amaral-Zettler LA, McCliment EA, Ducklow HW, Huse SM. A method for studying protistan diversity using massively parallel sequencing of V9 hypervariable regions of small-subunit ribosomal RNA genes. PLoS ONE. 2009;4:e6372.

57. Schloss PD, Westcott SL, Ryabin T, Hall JR, Hartmann M, Hollister EB, et al. Introducing mothur: open-source, platformindependent, community-supported software for describing and comparing microbial communities. Appl Environ Microbiol. 2009;75:7537-41.

58. De Vargas C, Audic S, Tara Oceans Consortium C, Tara Oceans Expedition P. Total V9 rDNA information organized at the metabarcode level for the Tara Oceans Expedition (2009-12). 2017. PANGAEA. https://doi.org/10.1594/PANGAEA.873277.

59. Ibarbalz FM, Henry N, Brandão MC, Martini S, Busseni G, Byrne $\mathrm{H}$, et al. Global trends in marine plankton diversity across kingdoms of life. Cell. 2019;179:1084-97.

60. Altschul SF, Gish W, Miller W, Myers EW, Lipman DJ. Basic local alignment search tool. J Mol Biol. 1990;215:403-10.

61. Katoh K, Rozewicki J, Yamada KD. MAFFT online service: multiple sequence alignment, interactive sequence choice and visualization. Brief Bioinform. 2019;20:1160-6.

62. Price MN, Dehal PS, Arkin AP. FastTree 2-approximately maximum-likelihood trees for large alignments. PLoS ONE. 2010;5:e9490.

63. Han MV, Zmasek CM. phyloXML: XML for evolutionary biology and comparative genomics. BMC Bioinform. 2009;10:356.

64. Templeton AR, Crandall KA, Sing CF. A cladistic analysis of phenotypic associations with haplotypes inferred from restriction endonuclease mapping and DNA sequence data. III. Cladogram estimation. Genetics. 1992;132:619-33.

65. Clement M, Posada D, Crandall KA. TCS: a computer program to estimate gene genealogies. Mol Ecol. 2000;9:1657-9.

66. Leigh JW, Bryant D. popart: full-feature software for haplotype network construction. Methods Ecol Evol. 2015;6:1110-6.

67. Nguyen L-T, Schmidt HA, von Haeseler A, Minh BQ. IQ-TREE: a fast and effective stochastic algorithm for estimating maximum-likelihood phylogenies. Mol Biol Evol. 2015;32:268-74.

68. Kalyaanamoorthy S, Minh BQ, Wong TKF, von Haeseler A, Jermiin LS. ModelFinder: fast model selection for accurate phylogenetic estimates. Nat Methods. 2017;14:587-9.

69. Tamura K, Stecher G, Peterson D, Filipski A, Kumar S. MEGA6: molecular evolutionary genetics analysis version 6.0. Mol Biol Evol. 2013;30:2725-9. 
70. Jukes TH, Cantor CR. Evolution of protein molecules. Mamm Protein Metab. 1969;3:21-132.

71. Meyer CP, Paulay G. DNA barcoding: error rates based on comprehensive sampling. PLoS Biol. 2005;3:e422.

72. R Core Team. R: a language and environment for statistical computing. 2019. Vienna, Austria: R Foundation for Statistical Computing; 2019.

73. McMurdie PJ, Holmes S. phyloseq: an R package for reproducible interactive analysis and graphics of microbiome census data. PLoS ONE. 2013;8:e61217.

74. Wickham H. ggplot2: elegant graphics for data analysis. New York: Springer-Verlag; 2016. https://ggplot2.tidyverse.org.

75. Becker A, Wilks AR. Maps: draw geographical maps. 2018. https://CRAN.R-project.org/package $=$ maps.

76. Markmann M, Tautz D. Reverse taxonomy: an approach towards determining the diversity of meiobenthic organisms based on ribosomal RNA signature sequences. Philos Trans R Soc Lond B Biol Sci. 2005;360:1917-24.

77. López-Escardó D, Paps J, de Vargas C, Massana R, Ruiz-Trillo I, Del Campo J. Metabarcoding analysis on European coastal samples reveals new molecular metazoan diversity. Sci Rep. 2018;8:9106.

78. Álvarez I, Wendel JF. Ribosomal ITS sequences and plant phylogenetic inference. Mol Phylogenet Evol. 2003;29:417-34.

79. Alverson AJ, Kolnick L. Intragenomic nucleotide polymorphism among small subunit (18S) rDNA paralogs in the diatom genus Skeletonema (Bacillariophyta). J Phycol. 2005;41:1248-57.

80. Gaonkar CC, Piredda R, Sarno D, Zingone A, Montresor M, Kooistra WHCF. Species detection and delineation in the marine planktonic diatoms Chaetoceros and Bacteriastrum through metabarcoding: making biological sense of haplotype diversity. Environ Microbiol. 2020;22:1917-29.

81. Cleve PT. Pelagisk Diatomeer från Kattegat. In: Petersen CGJ, editor. Det Videnskabelige Udbytte af Kanonbaaden 'Hauchs' Togter i de Danske Have Indefor Skagen, I. Aarene 1883-86. Kjøbenhavn: Andr. Fred. Høst \& Sons Forlag; 1889. pp 53-56.

82. Gran HH. Den Norske Nordhaus-Expedition 1876-1878. Botanik, Protophyta: Diatomaceae, Silicoflagellata og Cilioflagellata. Christiania: Grøndal \& Søns; 1897.

83. De Luca D, Kooistra WHCF, Sarno D, Gaonkar CC, Piredda R. Global distribution and diversity of Chaetoceros (Bacillariophyta, Mediophyceae): integration of classical and novel strategies. PeerJ. 2019;7:e7410.

84. Wang J, Wu J. Occurrence and potential risks of harmful algal blooms in the East China Sea. Sci Total Environ. 2009;407:4012-21.

85. Zhen Y, Mi T, Yu Z. Detection of several harmful algal species by sandwich hybridization integrated with a nuclease protection assay. Harmful Algae. 2009;8:651-7.

86. Richter DJ, Watteaux R, Vannier T, Leconte J, Frémont P, Reygondeau G, et al. Genomic evidence for global ocean plankton biogeography shaped by large-scale current systems. bioRxiv. 2019. https://doi.org/10.1101/867739.

87. Sarno D, Kooistra WHCF, Balzano S, Hargraves PE, Zingone A. Diversity in the genus Skeletonema (Bacillariophyceae). III. Phylogenetic position and morphological variability of Skeletonema costatum and Skeletonema grevillei, with the description of Skeletonema ardens sp. nov. J Phycol. 2007;43:156-70.

88. Hasle GR. The biogeography of some marine planktonic diatoms. Deep Sea Res Oceanogr Abstr. 1976;23:319-338, IN1IN6.

89. Pargana A. Functional and molecular diversity of the diatom family Leptocylindraceae. 2017. PhD Thesis, The Open University, Milton Keynes, UK.

90. Novis PM. Taxonomy of Klebsormidium (Klebsormidiales, Charophyceae) in New Zealand streams and the significance of low-pH habitats. Phycologia. 2006;45:293-301.

91. Rindi F, Guiry MD, López-Bautista JM. Distribution, morphology, and phylogeny of Klebsormidium (Klebsormidiales, Charophyceae) in urban environments in Europe. J Phycol. 2008;44:1529-40.

92. Rindi F, Mikhailyuk TI, Sluiman HJ, Friedl T, López-Bautista JM. Phylogenetic relationships in Interfilum and Klebsormidium (Klebsormidiophyceae, Streptophyta). Mol Phylogenet Evol. 2011;58:218-31.

93. Škaloud P, Rindi F. Ecological differentiation of cryptic species within an asexual protist morphospecies: a case study of filamentous green alga Klebsormidium (Streptophyta). J Eukaryot Microbiol. 2013;60:350-62.

94. Baas Becking LGM. Geobiologie of Inleiding tot de Milieukunde. The Hague: Van Stockum \& Zoon; 1934).

95. Shapiro BJ, Leducq J-B, Mallet J. What is speciation? PLoS Genet. 2016;12:e1005860.

96. Godhe A, Rynearson T. The role of intraspecific variation in the ecological and evolutionary success of diatoms in changing environments. Philos Trans R Soc Lond B Biol Sci. 2017;372:20160399.

97. de Vargas C, Norris R, Zaninetti L, Gibb SW, Pawlowski J. Molecular evidence of cryptic speciation in planktonic foraminifers and their relation to oceanic provinces. Proc Natl Acad Sci USA. 1999;96:2864-8.

98. Amato A, Kooistra WHCF, Levialdi Ghiron JH, Mann DG, Pröschold T, Montresor M. Reproductive isolation among sympatric cryptic species in marine diatoms. Protist. 2007;158:193-207.

99. Weisse T. Distribution and diversity of aquatic protists: an evolutionary and ecological perspective. Biodivers Conserv. 2007;17:243-59.

100. Vanelslander B, Créach V, Vanormelingen P, Ernst A, Chepurnov VA, Sahan E, et al. Ecological differentiation between sympatric pseudocryptic species in the estuarine benthic diatom Navicula phyllepta (Bacillariophyceae). J Phycol. 2009;45:1278-89. 